\title{
"Double-trouble" for respiratory control in Pompe disease
}

\author{
Ken D. O'Halloran* \\ School of Medicine and Medical Science, University College Dublin, Dublin, Ireland
}

*Correspondence: ken.ohalloran@ucd.ie

\section{A commentary on}

Hypoglossal neuropathology and respiratory activity in Pompe mice

by Lee, K.-Z., Qiu, K., Sandhu, M. S., Elmullah, M. K., Falk, D. J., Lane, M. A., Reier, P. J., Byrne, B. J., and Fuller, D. D. (2011). Front. Physiol. 2:31. doi: 10.3389/ fphys.2011.00031

Glycogen storage disease type II (Pompe disease) results from a widespread deficiency of acid $\alpha$-glucosidase (GAA) - the lysosomal enzyme essential for glycogen breakdown. Defects in the GAA gene result in extensive glycogen accumulation in visceral organs and skeletal muscle, including the striated muscles of respiration. Alas, respiratory insufficiency is common in Pompe patients (Mellies et al., 2005; Pellegrini et al., 2005; Mellies and Lofaso, 2009), many of whom require ventilatory support (Haley et al., 2003; Marsden, 2005); indeed nearly one in five Pompe infants die of respiratory failure (Byrne et al., 2011). Muscle pathology has traditionally been implicated in motor perturbations in Pompe disease, but compelling evidence is accruing implicating nervous system disturbances in the pathophysiology of the disorder. Glycogen accumulation is observed in nervous tissues of patients (Mancall et al., 1965; Gambetti et al., 1971; Martin et al., 1973; Martini et al., 2001; Teng et al., 2004; DeRuisseau et al., 2009) and animal models (Matsui et al., 1983; Sidman et al., 2008; DeRuisseau et al., 2009) of the disease. Of relevance to respiratory control, phrenic motor neuron pathology is reported in the $\mathrm{Gaa}^{-/-}$mouse (DeRuisseau et al., 2009) and cervical spinal cord (DeRuisseau et al., 2009) and brainstem (Mancall et al., 1965; Teng et al., 2004) pathology have been noted in Pompe patients postmortem. In this issue of Frontiers in Respiratory Physiology, Lee et al. (2011), explore further the respiratory phenotype of GAA-deficient mice providing evidence to suggest that respiratory perturbations in Pompe disease have a significant neurogenic component that extends to cranial motor neuronal pathways supplying key accessory muscles of respiration. The findings of this well-executed, basic science investigation have significant implications for treatment strategies in glycogen storage disease.

Using an established transgenic mouse model, Lee et al. (2011) tested the hypothesis that systemic GAA deficiency results in glycogen accumulation in the cell bodies of motor neurons of the hypoglossal (XII) nucleus concomitant with impaired efferent respiratory neural discharge. Brainstem histology revealed widespread neuropathology as evidenced by extensive glycogen accumulation in neuronal cell bodies within the hypoglossal nucleus and other structures such as the nucleus ambiguus; PAS-positive reaction product was also identified in sustentacular cells of the medullary network. Neurophysiological experiments in anesthetized mice revealed that compared to wild-type controls, $\mathrm{Gaa}^{-/-}$mice exhibit instability in neural circuits controlling respiratory timing, manifest as increased variability in respiratory motor output. Moreover, the authors observed a significant decrease in integrated efferent traffic (drive) to upper airway dilator muscles critical in the control and maintenance of pharyngeal airway caliber. The latter was revealed following bilateral vagotomy and removal of volume-related feedback inhibition of respiratory motor output.

These novel observations concerning motor control of the upper airway in the $\mathrm{Gaa}^{-/-}$mouse raise intriguing questions concerning respiratory morbidity in Pompe disease. For example, is there a general blunting of spinal and cranial motor outflow in response to key respiratory-related cues to the central respiratory network such that airway mechanoreflex and airway and arterial chemoreflex recruitment of cranial motor drive is depressed in Pompe patients? This has considerable clinical relevance given that impaired neural control of the pharyngeal airway muscles increases the risk of airway obstructive events. Such changes could explain the high prevalence of obstructive sleep apnea in Pompe patients (Margolis et al., 1994).

To conclude, Lee et al.'s (2011) observations raise the ante considerably concerning the pathophysiology and treatment of Pompe disease. The evidence points to "double-trouble" for respiration. Not alone is there impairment in the physiological function of the effector organs of the control system - the thoracic pump and airway dilator muscles whose co-ordinated activity is essential for effective pulmonary ventilation, but the spinal and brainstem motor systems that precisely control the effectors are also adversely affected. This coupled to the suggestion that respiratory rhythmogenesis and pattern generation are also perturbed, at least in mice, paints a devastating portrait of the "perfect storm" for breathing in Pompe disease. The major challenge is to overcome it. The paper by Lee et al. (2011) suggests that therapeutic strategies targeting the nervous system may be necessary to correct respiratory-related deficits in this devastating disease.

\section{REFERENCES}

Byrne, B. J., Kishnani, P. S., Case, L. E., Merlini, L., MullerFelber, W., Prasad, S., and der Ploeg, A. (2011). Pompe disease: design, methodology, and early findings from the Pompe registry. Mol. Genet. Metab. 103, 1-11.

DeRuisseau, L. R., Fuller, D. D., Qiu, K., DeRuisseau, K. C., Donnelly, W. H. Jr., Mah, C., Reier, P. J., and Byrne, B. J. (2009). Neural deficits contribute to respiratory insufficiency in Pompe disease. Proc. Natl. Acad. Sci. U.S.A. 106, 9419-9424.

Gambetti, P., DiMauro, S., and Baker, L. (1971). Nervous system in Pompe's disease. Ultrastructure and biochemistry. J. Neuropathol. Exp. Neurol. 30, 412-430.

Haley, S. M., Fragala, M. A., and Skrinar, A. M. (2003). Pompe disease and physical disability. Dev. Med. Child Neurol. 45, 618-623.

Lee, K.-Z., Qiu, K., Sandhu, M. S., Elmullah, M. K., Falk, D. J., Lane, M. A., Reier, P. J., Byrne, B. J., and Fuller, D. D. (2011). Hypoglossal neuropathology and respiratory activity in Pompe mice. Front. Physiol. 2:3. doi: 10.3389/fphys.2011.00031

Mancall, E. L., Aponte, G. E., and Berry, R. G. (1965) Pompe's disease (Diffuse Glycogenosis) with neuronal storage. J. Neuropathol. Exp. Neurol. 24, 85-96.

Margolis, M. L., Howlett, P., Goldberg, R., Eftychiadis, A., and Levine, S. (1994). Obstructive sleep apnea syndrome in acid maltase deficiency. Chest 105 , 947-949. 
Marsden, D. (2005). Infantile onset Pompe disease: a report of physician narratives from an epidemiologic study. Genet. Med. 7, 147-150.

Martin, J. J., de Barsy, T., van Hoof, F., and Palladini, G. (1973). Pompe's disease: an inborn lysosomal disorder with storage of glycogen. A study of brain and striated muscle. Acta Neuropathol. 23, 229-244.

Martini, C., Ciana, G., Benettoni, A., Katouzian, F., Severini, G. M., Bussani, R., and Bembi, B. (2001). Intractable fever and cortical neuronal glycogen storage in glycogenosis type 2. Neurology 57 , 906-908.

Matsui, T., Kuroda, S., Mizutani, M., Kiuchi, Y., Suzuki, K., and Ono, T. (1983). Generalized glycogen storage disease in Japanese quail (Coturnix coturnix japonica). Vet. Pathol. 20, 312-321.
Mellies, U., and Lofaso, F. (2009). Pompe disease: a neuromuscular disease with respiratory muscle involvement. Respir. Med. 103, 477-484.

Mellies, U., Stehling, F., Dohna-Schwake, C., Ragette, R., Teschler, H., and Voit, T. (2005). Respiratory failure in Pompe disease: treatment with noninvasive ventilation. Neurology 64, 1465-1467.

Pellegrini, N., Laforet, P., Orlikowski, D., Pellegrini, M., Caillaud, C., Eymard, B., Raphael, J. C., and Lofaso, F. (2005). Respiratory insufficiency and limb muscle weakness in adults with Pompe's disease. Eur. Respir. J. 26, 1024-1031.

Sidman, R. L., Taksir, T., Fidler, J., Zhao, M., Dodge, J. C., Passini, M. A., Raben, N., Thurberg, B. L., Cheng, S. H., and Shihabuddin, L. S. (2008). Temporal neuropathologic and behavioral phenotype of $6^{\text {neo/6neo }}$ Pompe disease mice. J. Neuropathol. Exp. Neurol. 67, 803-818.
Teng, Y. T., Su, W. J., Hou, J. W., and Huang, S. F. (2004). Infantile-onset glycogen storage disease type II (Pompe disease): report of a case with genetic diagnosis and pathological findings. Chang Gung Med. J. 27, 379-384.

Received: 30 July 2011; accepted: 12 August 2011; published online: 01 September 2011.

Citation: O'Halloran KD (2011) “Double-trouble" for respiratory control in Pompe disease. Front. Physio. 2:54. doi: 10.3389/fphys.2011.00054

This article was submitted to Frontiers in Respiratory Physiology, a specialty of Frontiers in Physiology.

Copyright (c) 2011 O'Halloran. This is an open-access article subject to a non-exclusive license between the authors and Frontiers Media SA, which permits use, distribution and reproduction in other forums, provided the original authors and source are credited and other Frontiers conditions are complied with. 